\title{
THE ENGINEERING METHOD FOR UNIFYING GROUND FLOOR SLAB SETTLEMENTS
}

\author{
Kęstutis URBONAS ${ }^{\star}$, Danutė SLIŽYTE ${ }^{2}$, Antanas ŠAPALAS ${ }^{1}$ \\ ${ }^{1}$ Department of Steel and Composite Structures, \\ Vilnius Gediminas Technical University, Vilnius, Lithuania \\ ${ }^{2}$ Department of Reinforced Concrete Structures and Geotechnics, \\ Vilnius Gediminas Technical University, Vilnius, Lithuania
}

Received 15 December 2020; accepted 25 January 2021

\begin{abstract}
For industrial buildings and logistics centres truck lifts are usually used. Therefore, there are special requirements for flatness tolerance of ground floor. The ground floor settlements differences in selected distances are limited. The article reviews the behaviour of soils and the importance of the actual behaviour assessment of soils during the design of floor slab on elastic subgrade. Particular attention is given to the behaviour of floor slab areas above pile foundations that support the building's columns. Calculation results show the impact of subgrade stiffness on the behaviour of the floor slab, especially in areas above pile foundations, where the stiffness of subgrade is much higher. The article presents a solution for achieving the required level of settlements' differences in areas where pile foundations for the building's columns under the ground slab are used. The paper proposes an efficient engineering method to reduce ground slab settlements differences. The results of performed calculations confirm the efficiency of presented method.
\end{abstract}

Keywords: ground floor slab, subgrade reaction coefficient, settlements of the ground floor slab, settlements of piles, flatness of floor slab, numerical modelling.

\section{Introduction}

Modern construction industry focuses on the rational design of structural elements and buildings. Ground floor slab is a very important complex structural element, especially for industrial buildings and logistics centres where truck lifts are used. Calculating ground floor settlements is a common task for structural designers. In general, deformations and reinforcement intensity of reinforced concrete (RC) slab on elastic subgrade depend on the slab's stiffness and subgrade deformability (Shadravan et al., 2015). When compiling the calculation scheme for a slab on a deformable subgrade, one encounters two problems: the nature of the distribution of the reactive pressure under the ground slab and the loading on the slab. Settlements depend directly on the stiffness of subgrade and rigidity of the slab. The subgrade of the ground floor slab is a heterogeneous material, and its deformation characteristics depend on many parameters and factors (Bhaduri \& Choudhury, 2020; Gunerathne et al., 2019).

All layers of soil have an influence on the calculation results. In theory, the thickness of elastic half space is un- limited. In reality, only the upper layers of the soils deform (Ardah et al., 2017). In general, the deformations of soil decrease with depth. The thickness of deformed soil is limited. It may be assumed that only a layer of certain thickness will deform. The layer's thickness depends on the loading area and the characteristics of soil (Tomasovicova \& Jendzelovsky, 2017). One of the solutions is to assume that the deformation modulus increases with depth. In addition, calculation results are affected by the variety of soils. Different varieties of soils have different characteristics. These are very important and must be assessed. Usually, the size and layout of the load can vary. For this reason, the changes of the load's layout and size within certain limits must be evaluated during calculations. Most often, the upper layers of the subgrade are compacted. If it is impossible to compact, weak upper soils can be replaced and then compacted (Al-Adhadh et al., 2019). As an alternative to the weak soils' replacement, chemical stabilization or soil reinforcement using rigid inclusions (Ardah et al., 2017) can be used. As an additional option

*Corresponding author. E-mail: kestutis.urbonas@vilniustech.lt 
for extremely weak soils, the floor slab can be supported on piles (Urbonas et al., 2016). In this case, the settlements of the slab could be greatly reduced and the differences of relatively small settlements would not exceed limit values. The slab must be sufficiently thick and heavily reinforced, moreover, a large quantity of piles may be needed. Therefore, such a method is expensive and not widely used when other solutions are possible.

Joints in the industrial floors cannot be avoided. The floor slab must be divided into segments of a given size. The size of these segments is limited. Number and type of joints depends on the floor construction method. The segments are connected by floor joints. The purpose of joints is to intercept tensile stresses caused by drying shrinkage and temperature changes inside the slab as well as to provide breaks in the construction process. The number and type of joints depend on the floor construction methods. The fibro concrete is increasingly used when installing floors. Fibres allow increasing the size of segments.

The floor slab must satisfy the strength (EN 1992-1-1 (European Committee for Standardization, 1992)) and the flatness tolerance requirements which depend on the type of equipment used. The tolerance requirements are especially important if lift trucks will be in use. These requirements depend on the type of lift trucks. These requirements according to DIN 15185 (Deutsches Institut für Normung, 1991) are presented in Tables 1 and 2.

Table 1. Flatness tolerance across the driving track for truck lift of the height $>6.0 \mathrm{~m}$

\begin{tabular}{|c|c|c|c|}
\hline \multicolumn{4}{|c|}{ Truck width $S$} \\
\hline$S \leq 1.0$ & $1<S \leq 1.5$ & $1.5<S \leq 2.0$ & $2.0<S \leq 2.5$ \\
\hline $1.5 \mathrm{~mm}$ & $2.0 \mathrm{~mm}$ & $2.5 \mathrm{~mm}$ & $3.0 \mathrm{~mm}$ \\
\hline
\end{tabular}

Table 2. Flatness tolerance lengthwise of the driving tracks

\begin{tabular}{|l|l|l|l|}
\hline \multicolumn{4}{|c|}{ Truck length $S_{p}$} \\
\hline$S_{p} \leq 1.0$ & $S_{p} \leq 2.0$ & $S_{p} \leq 3.0$ & $S_{p} \leq 4.0$ \\
\hline $2.0 \mathrm{~mm}$ & $3.0 \mathrm{~mm}$ & $4.0 \mathrm{~mm}$ & $5.0 \mathrm{~mm}$ \\
\hline
\end{tabular}

If flatness requirements are not satisfied, lift trucks lifting the load up, can overturn. That is why especially for industrial buildings and logistics centres, where truck lifts are used, floor slab flatness tolerance requirements are especially important.

\section{Influence of support conditions on the slab behaviour}

Floor settlement differences may occur not only due to different soil compressibility and inadequate support condition (El-Garhy et al., 2018). The ground floor slabs are not only laid on soil but could be also partially supported by the columns' or the walls' foundations. The settlement of ground floor slabs and columns' or walls' foundations differ from each other. Very often the columns and the walls are supported on pile foundations. The pile foundations' settlements are relatively very small (Nejad \& Jaksa,
2017; Jayarajan \& Kouzer, 2015). Thus, the settlements of the ground floor slab above the pile foundation will be very small, while in other places, the ground floor slab settle more (Xu et al., 2019). Therefore, the settlements of the ground floor slab are significantly different and the flatness requirements may not be kept. In such situation the settlements of the most deformed parts of the floor must be decreased or the settlements of parts over columns' or walls' foundations must be increased. The settlements can be decreased by replacing the weak soils, by using chemical stabilization, etc. Another way is deepening of the pile foundation to a level needed to ensure the sufficient magnitude of floor slabs deformation in the area above the pile foundations. The reduced deformability of soils and the deepened pile foundations can also be used together to achieve the required flatness that satisfies the tolerance requirements.

The behavior of the floor slab depends on loading (The Concrete Society, 2016), the thickness of the slab (Shadravan et al., 2015) and, of course, the stiffness characteristics of subgrade under the slab (Sall et al., 2013).

When the slab subgrade is stiffer, the settlements are smaller and the slab reinforcement is less intense. If the slab subgrade is less stiff, especially when slab areas are loaded differently, the slab settle unevenly and needs to be reinforced more intensely. In areas where slab settlements are limited (over pile foundations), reinforcement may be particularly intense and the differences of settlements between slab areas could not exceed the allowable and must meet certain requirements (Tables 1 and 2).

For unifying ground floor slab settlements thicker RC ground floor slab could be used as well. Investigations have shown that by increasing the thickness of the slab, the difference of the ground slab settlements reduces. Nevertheless, the maximum settlements decrease not significantly (Turskis et al., 2020). Applying such an engineering solution, the amount of concrete will increase significantly as well. That is why the thicker slab could not be applicable as a key solution to reducing the differences of the ground slab settlements.

\section{Modelling of the soil behaviour}

The modeling of soil behavior is mainly based on two theories: elastic half space and subgrade reaction. When using elastic half space theory, the equations of the elasticity theory apply. The surface deforms not only directly at places of added load, but also nearby. The main parameter of the ground deformability is the soil elasticity modulus $\mathrm{E}$ (MPa). The elasticity modulus can be determined by testing soil samples in the laboratory or directly in situ.

The subgrade reaction (known as Winkler) theory states that the settlement of the surface is proportional to the applied pressure $p$ (Winkler, 1867):

$$
p=C \cdot s
$$

where $C_{s}(\mathrm{MPa} / \mathrm{m})$ is the subgrade reaction coefficient; $s$ settlement of the surface. 
The settlement of the surface depends only on the pressure added at that point. The estimation of the values of the subgrade reaction coefficient $C_{s}$ is one of the most complex problems in geotechnical engineering. This coefficient is not just an index that characterizes the soil properties. It also depends on the subgrade loading scheme, foundation geometry, depth, and size (Marto et al., 2012).

In addition to other factors, the numerical value of the subgrade modulus correlates to the soil elasticity modulus E. The elementary explanation of the subgrade reaction coefficient is based on the theory of elasticity (Timoshenko \& Goodier, 1982). The elastic settlement $s$ of a flexible footing with the dimensions $l \times b$ (length $l>$ width $b$ ) is equal to:

$$
s=q b \frac{1-v^{2}}{E} I_{s},
$$

where $q$ - is the footing pressure; $v$ - Poisson's ratio; $I_{s}$ the influence factor depending on rigidity, the shape and $1 / \mathrm{b}$ ratio of the footing.

The Equation (2) can be rewritten as follows:

$$
k_{s}=\frac{q}{s}=\frac{E}{I_{s} b\left(1-v^{2}\right)} \text {. }
$$

The soil is infinitely deep and the soil elasticity modulus is assumed to be constant. The deformation will be smaller assuming that a layer of limited thickness will be compressed. An additional factor can be introduced into the evaluation when compressing a layer of finite thickness (Mayne \& Poulos, 1999).

The concept of the subgrade reaction coefficient has been presented in technical literature by many researchers (Terzaghi,1955; Vlasov \& Leontiev, 1960; Sadrekarimi \& Akbarzad, 2009; Elsamee, 2013).

The most commonly used is the one-parameter subgrade reaction coefficient. However, also two-parameter settings were proposed (Pasternak, 1954) as well as the layered half-space model (Piskunov \&Fedorenko, 1994).

Two-parameter theory uses the subgrade reaction coefficients $C_{1}$ (a compression ratio) and $C_{2}$ (a shear ratio) as shown in Figure 1.

$$
\begin{aligned}
& C_{1}=F_{z} \cdot \Delta z_{1} ; \\
& C_{2}=F_{z} \cdot \Delta z_{2} .
\end{aligned}
$$

According to Shashkin (1999), the subgrade reaction coefficients for two-parameter models for layered soil can be calculated as follows:

$$
\begin{aligned}
& C_{1}=\frac{1}{\delta_{\Sigma}} \\
& C_{2}=\frac{1}{3 \cdot \delta_{\Sigma}^{2}} \sum_{i=1}^{n} G_{i} h_{i}\left(\delta_{i}^{2}+\delta_{i} \delta_{i+1}+\delta_{i+1}^{2}\right) \\
& \delta_{\Sigma}=\sum_{j=1}^{n} \frac{h_{j}}{E_{j}} \\
& \delta_{i}=\frac{h_{i}}{E_{i}}
\end{aligned}
$$

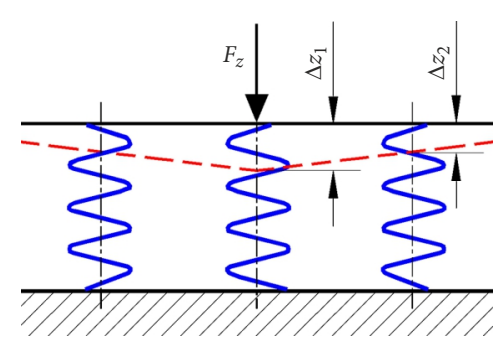

Figure 1. Visualization of $C_{1}(4)$ and $C_{2}(5)$ parameters

$$
\delta_{n+1}=0,
$$

where $h_{i}$ - thickness of soil layer $i, E_{i}$ - the modulus of deformation of layer $i, G_{i}$ is the modulus of the shear deformation of layer $i$ :

$$
G_{i}=\frac{E_{i}}{2\left(1+v_{i}\right)} .
$$

However, a different situation occurs when evaluating the subgrade reaction coefficients over the pile cap. In this case, the total settlement of the floor slab is the result of:

- the soil deformation between the piles' cap and the bottom of the slab;

- the settlement of the pile foundation due to additional loads.

These deformations can be evaluated separately.

The value of $\delta$ for soil between the pile cap and floor slab can be calculated using formula (8).

The pile foundation settlement is calculated under the assumption that a spring is used instead of the piles' foundation. The stiffness coefficient of which is equal $k_{s}$ :

$$
s_{p}=\frac{\sigma_{s z} \cdot A}{n \cdot k_{s}},
$$

where $A$ is the area of the piles' cap, $n$ the number of piles and $k_{s}$ the predicted pile stiffness coefficient (Luo et al., 2018). Then the Equation (10) in zone above the pile cap, must be changed to:

$$
\delta_{n+1}=\frac{1}{C_{1 p}}=\frac{s_{p}}{\sigma_{s z}}=\frac{A}{n \cdot k_{s}} .
$$

The structural analysis software commonly models the soil by using subgrade reaction coefficients. The elastic modelling of the soil subgrade is based on assumptions about the behaviour of the subgrade reaction under loading. The most widely used relation between forces and deformations is linear, because of the simplicity of the equations' solution.

\section{Numerical example}

Numerical calculations were performed according to real situation and is based on the slab calculations for one logistic centre. A variety of floor slab calculations were performed. Under the slab lying ground layers as shown in Figure 2. Ground properties are described in Table 3. The top of the pile caps can be under the part of the slab at three different depths. The slab's parameters used in the 
calculation: thickness of the RC slab $-0.2 \mathrm{~m}$; the weight density of the slab $-25 \mathrm{kN} / \mathrm{m}^{3}$; Elasticity modulus of material of the slab - $31 \mathrm{GPa}$.

The slab was loaded by uniformly distributed load of $50 \mathrm{kPa}$ and concentrated loads from the shelving supports as shown in Figure 3a. Piles' cap and piles geometry and position is shown in Fragment "A" in Figure 3b. The main purpose of the calculation was to determine the dependence of the deformations of the ground slab on the depth of the pile foundation.

For ground slab analysis software package Plaxis 3D was used. This software is suitable for geotechnical problem solving. Analysis is based on direct evaluation of soil characteristics and uses elastic half space theory. The Mohr-Coulomb model was used for the performed analysis. The yield surface of this model is an extension of the Coulomb's friction law to the general states of stress (the manual of Plaxis 3D). Figure 4 shows the settlement distribution of the modelled fragment "A" of the RC slab when the pile cap is in-depth of $0.25,0.60$ and $1.20 \mathrm{~m}$. Positions of piles' cap and loads see Figure 3. As could be seen, settlements of the floor slab in the center of the fragment are larger when pile cap is deeper and opposite, settlements in the centre are smaller the higher the pile cap is. Settlements differences at the edges of the fragment are relatively small, and the farther from the center, the differences decrease.

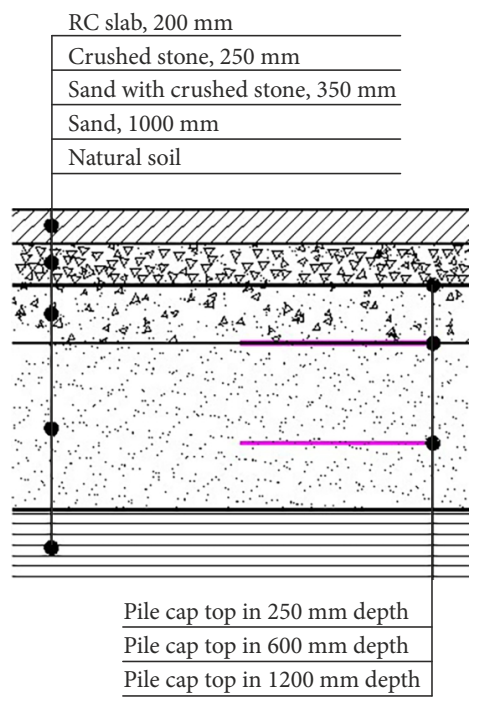

Figure 2. Subgrade construction and the depth of the top level of the pile cap

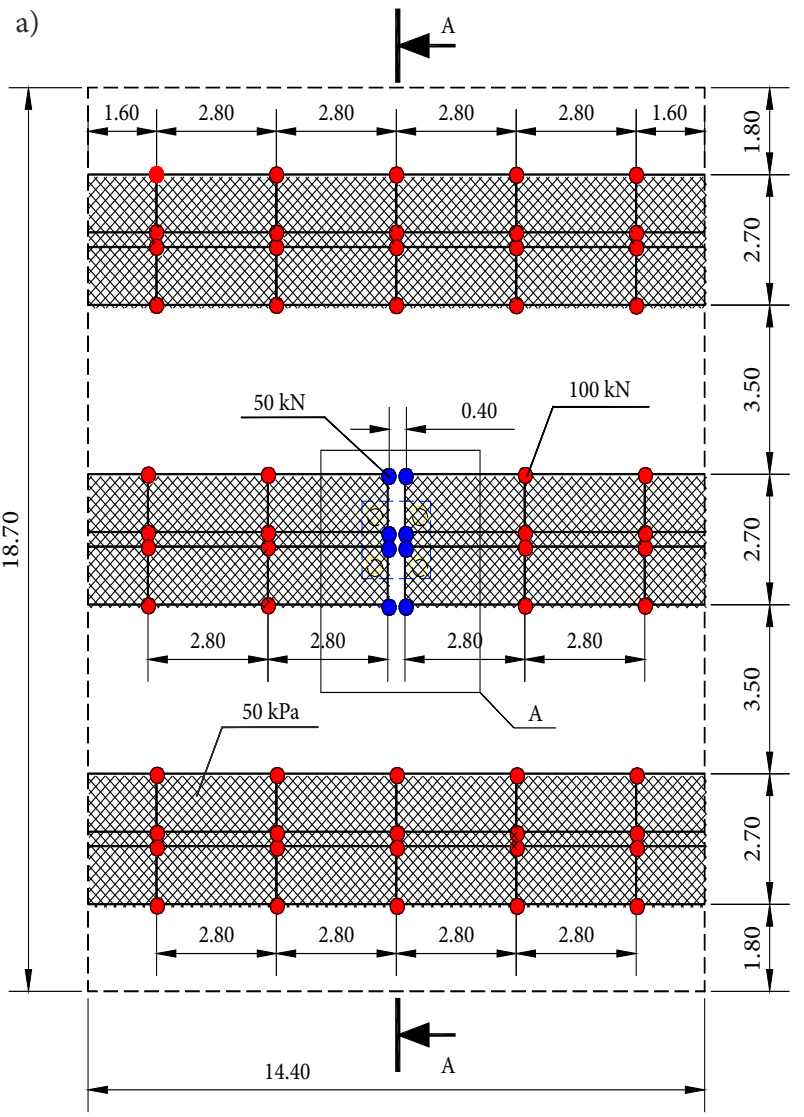

b)

Fragment "A" $(2.1 \times 2.7 \mathrm{~m})$

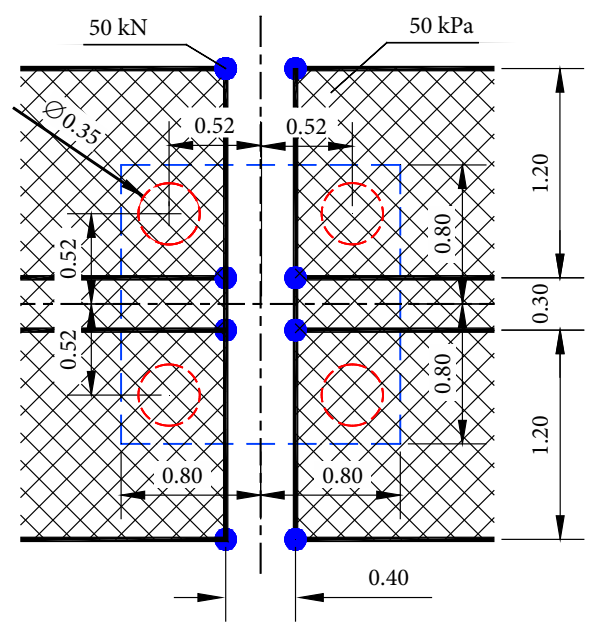

Figure 3. a - Layout of concentrated loads (reference to section A-A see Figure 5); b - Fragment "A" with the position of the piles and the piles'cap

Table 3. Soil properties

\begin{tabular}{|l|c|c|c|c|c|}
\hline \multicolumn{1}{|c|}{ Layer } & Crushed stone & Gravel with crushed stone & Sand, compacted & Clay (1) & Clay (2) \\
\hline Thickness, $H(\mathrm{~m})$ & 0.25 & 0.35 & 1.00 & 0.60 & 7.8 \\
\hline Cohesion, $c(\mathrm{kPa})$ & 1 & 1 & 1 & 25 & 28 \\
\hline Angle of internal friction, $\varphi(\mathrm{deg})$ & 43 & 40 & 38 & 19 & 22 \\
\hline Density, $\gamma\left(\mathrm{kN} / \mathrm{m}^{3}\right)$ & 19.8 & 19.2 & 19 & 19.4 & 19.4 \\
\hline Poisson coefficient, $v(-)$ & 0.3 & 0.3 & 0.3 & 0.3 & 0.3 \\
\hline Elasticity modulus, $E_{\text {ref }}(\mathrm{MPa})$ & 180 & 80 & 32 & 16 & 22 \\
\hline
\end{tabular}


Figures 5 and 6 show the values of bending moments in the modelled fragment " $\mathrm{A}$ " when the pile cap is in-depth of $0.25,0.60$ and $1.20 \mathrm{~m}$. The bending moments directly determine the reinforcement intensity of the RC slab. The larger the settlement differences, the values of bending moments in the slab are higher. Consequently, the more reinforcement will be required to reinforce the slab.
The analysis of the settlements and distribution of bending moments in the modelled fragment " $\mathrm{A}$ " has shown that by deepening the piles' foundation and equalizing the stiffness of the subgrade, it is possible not only to achieve the requirements of flatness, but also to reduce the amounts of slab reinforcement.
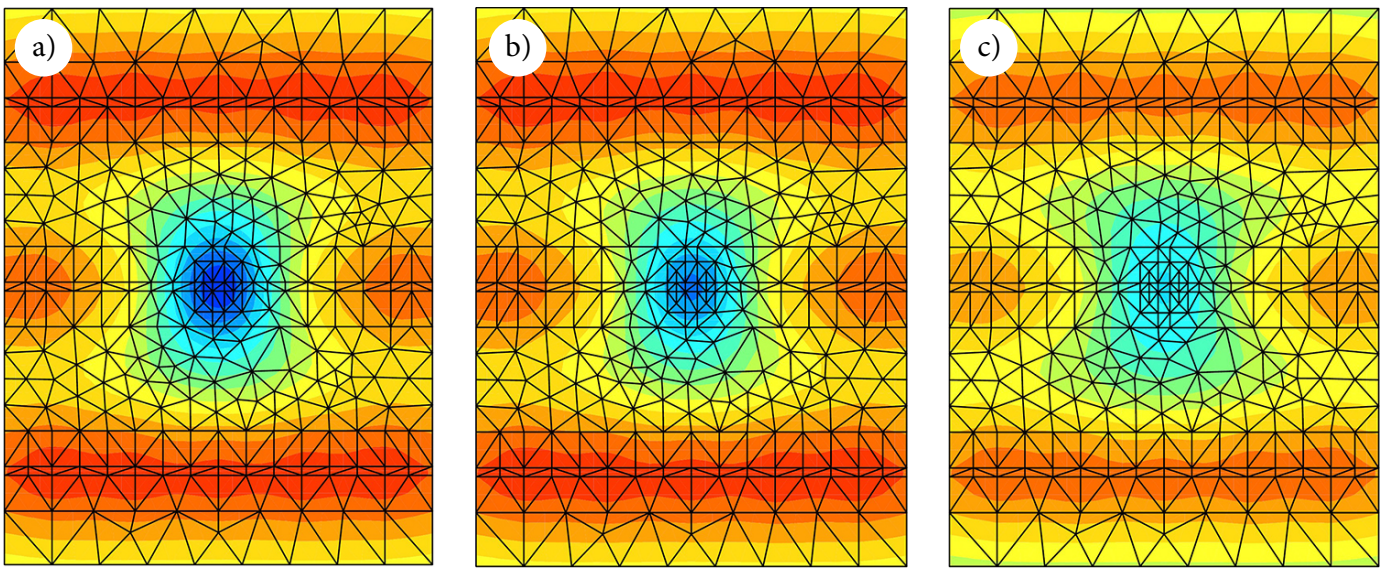

d)

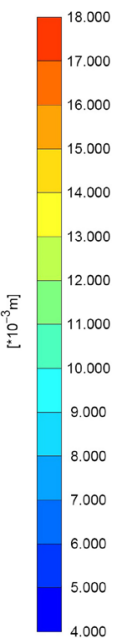

Figure 4. Settlements of the fragment "A" of the slab when the piles' cap is in depth of: $a-0.25 ; b-0.60$; $\mathrm{c}-1.20 \mathrm{~m}$; $\mathrm{d}$ - scale of the settlements $(\mathrm{mm})$
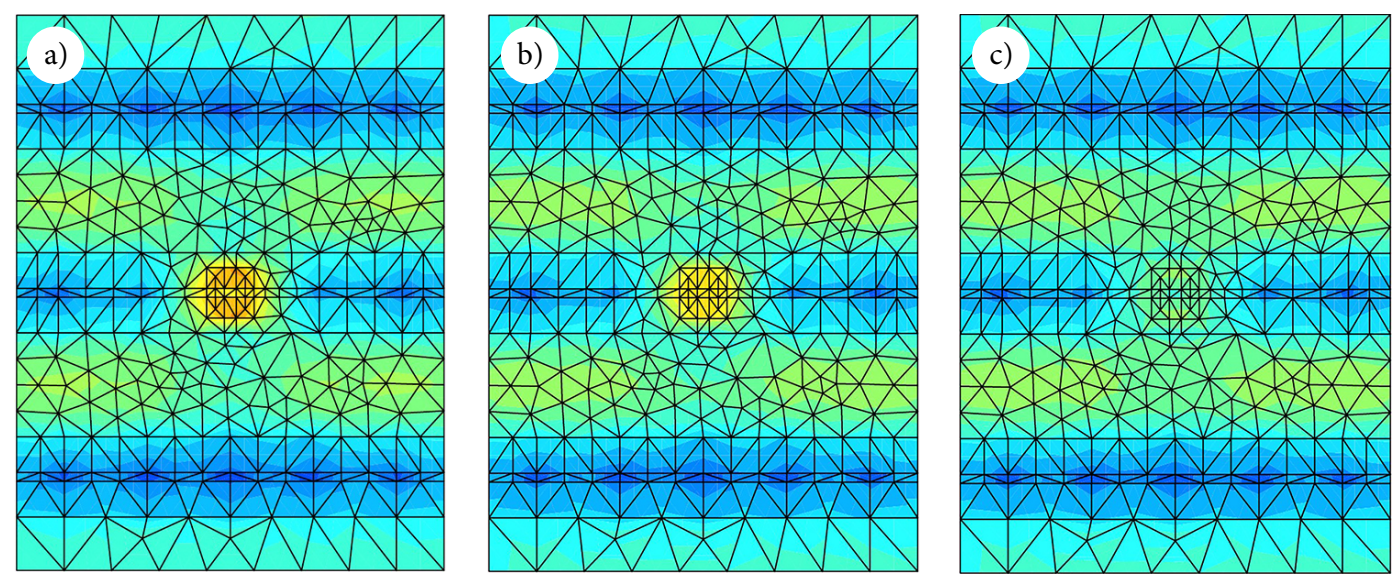

Figure 5. Distribution of bending moments in the RC slab in the direction $\mathrm{Y}$ of the fragment " $\mathrm{A}$ " of the slab when the piles' cap is in depth of: $\mathrm{a}-0.25 ; \mathrm{b}-0.60 ; \mathrm{c}-1.20 \mathrm{~m} ; \mathrm{d}-$ scale of the bending moment $(\mathrm{kNm} / \mathrm{m})$
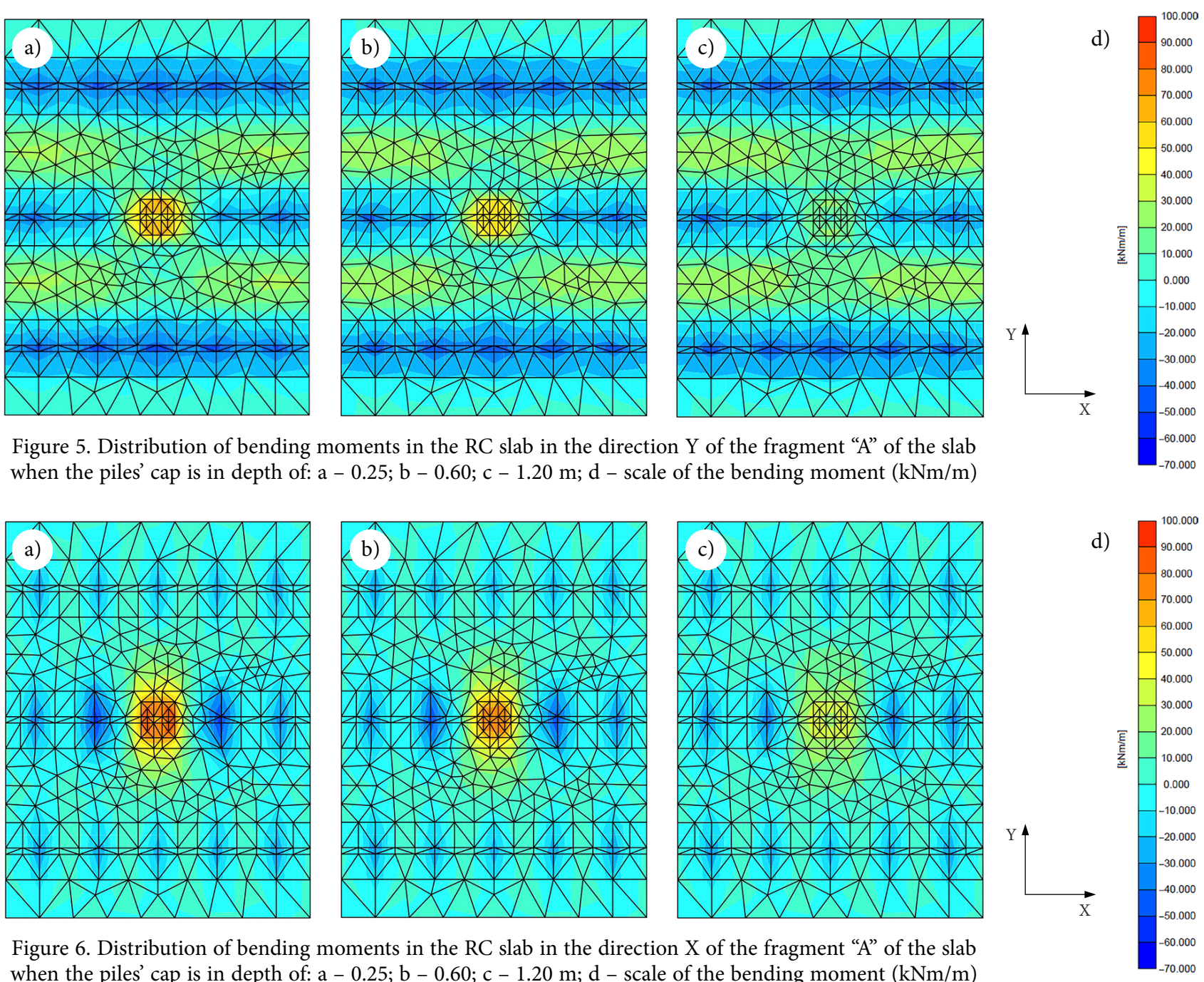

Figure 6. Distribution of bending moments in the RC slab in the direction X of the fragment "A" of the slab when the piles' cap is in depth of: $\mathrm{a}-0.25 ; \mathrm{b}-0.60 ; \mathrm{c}-1.20 \mathrm{~m} ; \mathrm{d}-$ scale of the bending moment $(\mathrm{kNm} / \mathrm{m})$ 


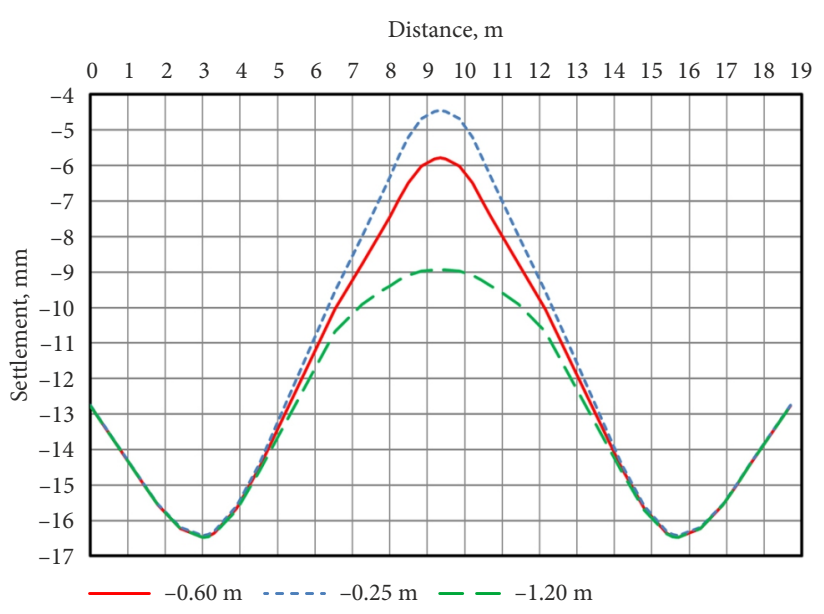

Figure 7. Settlements of the slab in the A-A section when the pile cap is at a different depth

Full-width floor slab settlements calculation (Turskis et al., 2020) tasks were performed using popular structural analysis software, that is based on subgrade reaction theory. Two-parameter theory models were used for the calculations. The results are shown in Figure 7 (layout of section A-A see in Figure 3a). These results corelates to the results of relatively small fragment "A". It is clearly seen that settlements differ more only in the area above pile cap. The difference of the settlements decreases farther from piles' area.

Slab's settlements above the foundation when subgrade is $0.25 \mathrm{~m}, 0.60 \mathrm{~m}$, and $1.20 \mathrm{~m}$ thickness, are equal respectively to $-4.74 \mathrm{~mm},-6.06 \mathrm{~mm}$, and $-8.99 \mathrm{~mm}$. The settlements will be more uniform if the above pile cap subgrade layer is thicker.

The settlement distribution and values using specialized geotechnical software Plaxis 3D and the structural analysis software based on two-parameter theory were practically identical. All the obtained calculations results confirm the efficiency of piles' cap depth increase as an effective way to reduce ground slab settlements differences.

As it could be stated, the main issue is to eliminate differences of floor slab settlements if those according to the requirements are exceeded. This research has shown, that increase of piles' cap depth is an efficient engineering solution for such issue.

\section{Comments and conclusions}

1. Different floor slab deformations could be caused not only by the loads and the characteristics of ground layers but also by the different support conditions. Pile foundation could cause significantly different changes in the support conditions, increase the stiffness of subgrade, and reduce settlements of the slab in a particular area. Especially different is the stiffness of subgrade that can be found over the pile foundation of the main columns of the building. In this case, the subgrade above the pile cap is relatively stiff and the floor slab settlements will be small.
2. The higher rigidity of the ground slab could be achieved by increasing thickness of the slab. The more rigid ground floor slab reduces the difference of the ground slab settlements. Neverthless, the amount of concrete will increase significantly. However, this method could by effective not enough. That is why this engineering solution could not be applicable as a key solution to reduce the differences of the ground slab settlements.

3. The increased settlements of the less deformed parts of the slab could be a solution to reduce the settlement differences to a certain level and the slab flatness will not exceed the permissible requirements. The calculation results show that the pile cap descent into deeper soil layers decrease the stiffness of subgrade over the piles. The ground slab in area over the piles settle more and consequently this change allows to reduce the differences of the ground floor slab settlements.

4. For large practical tasks, it is recommended to use the subgrade reaction coefficient with two parameters which can successfully supplement the modelling using finite elements. The settlement distribution and values using specialized geotechnical software Plaxis 3D and the structural analysis software based on two-parameter theory were practically identical.

\section{References}

Al-Adhadh, A. R., Kadhim, Z. J., \& Naeem, Z. T. (2019). Reviewing the most suitable Soil Improvement Techniques for treating soft clay soil. Journal of Engineering Research and Application, 9(8), 1-11.

Ardah, A., Chen, Q., \& Abu-Farsakh, M. (2017). Evaluating the performance of very weak subgrade soils treated/stabilized with cementitious materials for sustainable pavements. Transportation Geotechnics, 11, 107-119. https://doi.org/10.1016/j.trgeo.2017.05.002

Bhaduri, A., \& Choudhury, D. (2020). Serviceability-based finiteelement approach on analyzing combined pile-raft foundation. International Journal of Geomechanics, 20(2). https://doi.org/10.1061/(ASCE)GM.1943-5622.0001580

Deutsches Institut für Normung (1991). Warehouse systems with guided industrial trucks: requirements on the ground, the warehouse and other requirements (DIN 15185). 7. (In German).

El-Garhy, B., Galil, A. A., \& Mari, M. (2018). Analysis of flexible raft resting on soft soil improved by granular piles considering soil shear interaction. Computers and Geotechnics, 94, 169-183. https://doi.org/10.1016/j.compgeo.2017.09.007

Elsamee, W. N. A. (2013). An experimental study on the effect of foundation depth, size and shape on subgrade reaction of cohessionless soil. Engineering, 5(10), 785-795.

https://doi.org/10.4236/eng.2013.510095

European Committee for Standardization. (1992). Eurocode 2: Design of concrete structures - Part 1-1: General rules and rules for buildings (EN 1992-1-1).

Gunerathne, S., Seo, H., Lawson, W. D., \& Jayawickrama, P. W. (2019). Variational approach for settlement analysis of circular plate on multilayered soil. Applied Mathematical Modelling, 70, 152-170. https://doi.org/10.1016/j.apm.2019.01.009

Jayarajan, P., \& Kouzer, K. M. (2015). Analysis of piled raft foundations. Indian Journal of Science, 16(51), 51-57. 
Luo, R., Yang, M., \& Li, W. (2018). Normalized settlement of piled raft in homogeneous clay. Computers and Geotechnics, 103, 165-178. https://doi.org/10.1016/j.compgeo.2018.07.023

Mayne, P. W., \& Poulos, H. G. (1999). Approximate displacement influence factors for elastic shallow foundation. Journal of Geotechnical and Geoenvironmental Engineering, 129(6), 453-460. https://doi.org/10.1061/(ASCE)1090-0241(1999)125:6(453)

Marto, A., Latifi, N., Janbaz, M., Kholghifard, M., Khari, M., Alimohammadi, P., \& Banadaki, A. D. (2012). Foundation size effect on modulus of subgrade reaction on sandy soils. Electronic Journal of Geotechnical Engineering, 17, 2523-2530.

Nejad, F. P., \& Jaksa, M. B. (2017). Load-settlement behavior modeling of single piles using artificial neural networks and CPT data. Computers and Geotechnics, 89, 9-21. https://doi.org/10.1016/j.compgeo.2017.04.003

Pasternak, P. L. (1954). Basics of a new method for analyzing foundations on elastic beds using two subgrade reaction coefficients. Moscow "Gosstroyizdat".

Piskunov, V. G., \& Fedorenko, Y. M. (1994) A dynamic method for monitoring layered slabs on elastic beds. Architecture and Construction in Belarus, (5-6), 10-22.

Sadrekarimi, J., \& Akbarzad, M. (2009). Comparative study of methods of determination of coefficient of subgrade reaction. Electronic Journal of Geotechnical Engineering, 14, 1-14.

Sall, O. A., Fall, M., Berthaud, Y., \& Ba, M. (2013). Influence of the elastic modulus of the soil and concrete foundation on the displacements of a mat foundation. Open Journal of Civil Engineering, 3(4), 228-233.

https://doi.org/10.4236/ojce.2013.34027

Shadravan, S., Ramseyer, C., \& Kang, T. H. K. (2015). A long term restrained shrinkage study of concrete slabs on ground. Engineering Structures, 102, 258-265. https://doi.org/10.1016/j.engstruct.2015.08.018

Shashkin, K. G. (1999). Using simplified foundation models for coupled analysis of a structure together with its foundation (In Russian) http://www.georec.narod.ru/mag/1999n1/9.htm

Terzaghi, K.V. (1955). Evaluation of coefficient of subgrade reaction. Geotechnique, 5(4), 297-326.

https://doi.org/10.1680/geot.1955.5.4.297

The Concrete Society. (2016). Concrete industrial ground floors A guide to design and construction (Concrete Society Technical Report No. 34).

Timoshenko, S. P., \& Goodier, J. N. (1982). Theory of elasticity (3h ed.). McGraw-Hill.

Tomasovicova, D., \& Jendzelovsky, N. (2017). Stiffness analysis of the subsoil under industrial floor. Procedia Engineering, 190, 365-370. https://doi.org/10.1016/j.proeng.2017.05.350

Turskis, Z., Urbonas, K., Sližyte, D., Medzvieckas, J., Mackevičius, R., \& Šapalas, V. (2020). A novel integrated approach to solve industrial ground floor design problems. Sustainability, 12(12), 4809. https://doi.org/10.3390/su12124809

Urbonas, K., Sližyte, D., \& Mackevičius, R. (2016). Influence of the pile stiffness on the ground slab behaviour. Journal of Civil Engineering and Management, 22(5), 690-698. https://doi.org/10.3846/13923730.2016.1176597

Vlasov, V. Z., \& Leontiev, N. N. (1960). Beams, plates, and shells on elastic beds. Physmathgiz. (In Russian).

Winkler, E. (1867). Die Lehre von Elastizitat and Festigkeit [on elasticity and fixity]. Prague.

Xu, L., Shao, W., Xue, Y., Cai, F., \& Li, Y. (2019). A simplified piecewise-hyperbolic softening model of skin friction for axially loaded piles. Computers and Geotechnics, 108, 7-16. https://doi.org/10.1016/j.compgeo.2018.12.018 